\title{
FOUCAULT: PODER, VIGILÂNCIA, DISCIPLINA E PUNIÇÃO UMA ANÁLISE DO CONCEITO DE PANÓPTICO EM OBRA NARRATIVA DE FICÇÃO
}

\author{
FOUCAULT: PODER, VIGILANCIA, DISCIPLINA Y \\ PUNICIÓN UNA ANÁLISIS DEL CONCEPTO DE \\ PANÓPTICO EN OBRA NARRATIVA DE FICCIÓN
}

\author{
Mariana da Silva Caprioli* \\ Larissa de Mello Lima** \\ Daniel Martínez-Avila*** \\ João Batista Ernesto de Moraes ${ }^{\star * * *}$
}

\begin{abstract}
RESUMO:
Introdução: Os textos narrativos de ficção, como por exemplo o livro "Jogos Vorazes" de Suzanne Collins, eventualmente abordam conceitos e tópicos que poderiam ser de utilidade no estudo acadêmico da vigilância, punição, disciplina e poder. Objetivo: Realizar um paralelo entre o conceito de Panóptico concebido por Jeremy Bentham e trabalhado por Foucault em sua obra "Vigiar e Punir" com o livro "Jogos vorazes", partindo-se da hipótese que Panem, o país tratado na história do livro, parece ter sido inspirada no Panoptismo, ou no dispositivo Panóptico. Metodologia: Trata-se de um artigo de revisão que busca, em um primeiro momento, trazer uma descrição sobre a forma como Foucault utilizou o conceito de Panóptico em "Vigiar e Punir", para em um segundo momento aprofundar o conceito de Panóptico com relação à obra de ficção "Jogos vorazes" buscando elementos que corroborem a hipótese do artigo. Resultados: Pode-se perceber que as forças de vigilância, poder e disciplina que regem o Panóptico são concomitantes na obra de Foucault e na obra de ficção de Suzanne Collins, escrito em 2010, fazendo-nos perceber que os discursos do texto narrativo de ficção possuem consonância com o discurso científico da obra de Michel Foucault. Conclusões: Já que as obras de ficção podem apresentar elementos comuns aos trabalhos de não ficção. A representação de obras narrativas de ficção é algo que possui potencial importância no estudo de conceitos em áreas acadêmicas. Este aspecto precisa ser considerado e aprofundado na descrição de obras de ficção
\end{abstract}

\footnotetext{
*Mestrado em Ciência da Informação pela Universidade Estadual Paulista Júlio de Mesquita Filho (UNESP). E-mail: mariana.caprioli@gmail.com.

**Doutoranda em Ciência da Informação pela Universidade Estadual Paulista (UNESP). E-mail: larissalima.unesp@gmail.com.

***Doutor em Documentación pelo Universidad Carlos III de Madrid, Espanha.

Professor da Universidade Estadual Paulista (UNESP). E-mail: dmartinezavila@marilia.unesp.br.

****Doutor em Estudos Literários pela Universidade Estadual Paulista Júlio de Mesquita Filho. Professor da Universidade Estadual Paulista (UNESP). E-mail: prof.joao@gmail.com.
} 
Mariana da Silva Caprioli, Larissa de Mello Lima, Daniel Martínez-Avila, João Batista Ernesto de Moraes

Foucault: poder, vigilância, disciplina e punição uma análise do conceito de Panóptico em obra narrativa de ficção

Palavras-chave: Discurso Científico. Discurso Literário. "Vigiar e Punir". “Jogos vorazes". Representação temática do documento.

\section{INTRODUÇÃO}

Parte-se da problemática de que as inconsistências presentes no processo de recuperação da informação não são exclusivas de textos narrativos de ficção, mas também poder ser encontradas na questão de incompletudes ou desvios na representação da informação decorrentes dos fatores de erro, omissão ou contradição na análise posterior à representação temática de um documento.

Castañon Moreno (1992) afirma que isto se dá pelo fato de “(...) o bibliotecário se preocupar mais em ajustar-se a um sistema de classificação ou de indexação do que em desenvolver uma análise documental que lhe permita compreender o tema exposto no texto de uma obra". (MORAES, 2011), (MORAES; GUIMARÃES, 2006).

Sendo assim, parte-se do pressuposto de que o texto narrativo de ficção pode incluir diversos discursos que avançam de um ponto a outro e podem ser entendidos como uma obra na qual o escritor cria criteriosamente e seleciona os termos que irá representar seu contexto escolhido. O livro "Jogos Vorazes" de Suzanne Collins é um exemplo de texto narrativo de ficção que trabalha com conceitos e tópicos que poderiam ser de utilidade no estudo acadêmico da vigilância, punição, disciplina e poder. Em outras palavras, trabalha-se com um texto de ficção que, a fim de justificar cientificamente a presença de elementos e afinidade com trabalhos científicos de áreas como a filosofia, no caso de "Vigiar e Punir", e ser de utilidade para o processo de recuperação da informação.

Sendo assim, o presente artigo pretende demostrar as seguintes hipóteses: a presença de elementos científicos sobre vigilância, punição, disciplina e poder e a influência cientifica de Foucault no livro "Jogos Vorazes"; e a possibilidade de basear a descrição de texto narrativos de ficção em estudos científicos como o presente para justificar uma possível classificação de trabalhos de ficção com trabalhos de não ficção. 
Mariana da Silva Caprioli, Larissa de Mello Lima, Daniel Martínez-Avila, João Batista Ernesto de Moraes

Foucault: poder, vigilância, disciplina e punição uma análise do conceito de Panóptico em obra narrativa de ficção

O artigo foi estruturado da seguinte maneira: na seção 2 tratou-se da metodologia utilizada para desenvolver o estudo. Na seção 3 tratou-se da Representação da Informação e sua utilidade em unidades de informação e deficiência em representar obras narrativas de ficção, passando para as seções 4 e 5, nas quais se realizou a revisão de literatura descrevendo em um primeiro momento o livro "Vigiar e Punir" e suas definições de vigilância, punição, disciplina e poder, para tornar viável na seção seguinte a explicação sobre o conceito de Panóptico, a fim de explorar na seção 6 a relação entre a obra "Jogos Vorazes" e os conceitos utilizados por Foucault. Terminando com os resultados e discussões encontrados durante o desenvolvimento do artigo, e as conclusões.

\section{REPRESENTAÇÃO DA INFORMAÇÃO}

A representação da informação é uma das etapas do Tratamento Temático da Informação, para que esta possa ser recuperada posteriormente.

A representação da informação é um processo cognitivo que passa pelas etapas de percepção, identificação, interpretação, reflexão e codificação, não se tratando apenas de um processo técnico.

[...] a RI consiste em um processo que envolve a descrição física e de conteúdo de um objeto informacional, e a RC envolve uma análise de domínio que resulta em sistemas conceituais estruturados esquematicamente que são utilizados no processo de descrição de conteúdo na RI (PINHO;NASCIMENTO; MELO, 2015, p.115).

Desta forma, a representação da informação tem como principal característica a substituição de uma entidade linguística longa e complexa (que se trata do documento) por uma descrição abreviada (NOVELLINO, 1996). A autora ainda coloca que essa sumarização não é apenas uma solução prática para a quantidade de material presente em uma unidade de informação a ser representado, armazenado e recuperado, mas também é desejável, pois tem a função de demonstrar a essência do documento, funcionando como um artificio de enfatização das principais características considerando a recuperação 
Mariana da Silva Caprioli, Larissa de Mello Lima, Daniel Martínez-Avila, João Batista Ernesto de Moraes

Foucault: poder, vigilância, disciplina e punição uma análise do conceito de Panóptico em obra narrativa de ficção

sendo "a solução ideal para organização e uso da informação" (NOVELLINO, 1996, p.38). Bräscher e Café (2008) corroboram que envolve um conjunto de elementos descritivos que representam os atributos de um material informacional específico

Com relação ao texto narrativo de ficção, serão abordados os critérios que podem definir esse tipo de texto, sob a perspectiva na área de Ciência da Informação, começando por uma definição dada por Beghtol (1994).

A autora compreende o texto narrativo de fiç̧ão como criações da imaginação de seus criadores, colocando da seguinte forma:

The world of documents may be divided initially in a conventional way, i.e., those works that are thought to arise primarily from the imaginations of their creators and those that are thought to arise from a rational faculty. "Fiction" may in turn be operationally defined as works arising from the imagination that are written in narrative prose. In this context, "narrative" may be taken broadly to include discourses that progress in some sense from one point to another (BEGHTOL, 1994, p.7).

Acreditando na mesma perspectiva, García-Marco et. al. (2010) mostram que, deve-se nos lembrar que a fiç̧ão se trata, sim, de uma forma de manifestação artística presente em todas as civilizações e que vem sido estudada desde a Grécia antiga. E, dessa forma, “(...) muitos pesquisadores consideram isso como uma manifestação concreta de informações, estudando a estrutura de composição, por exemplo, apesar da ficção contar uma história sobre um lugar imaginário, como fez Swift em As Viagens de Gulliver" (GARCÍA-MARCO et. al., 2010, p. 264, tradução SABBAG, 2013, p. 45).

Precisa-se, ainda, compreender que para uma definição operacional que caiba na área de Ciência da Informação, não há, segundo Beghtol (1994), nenhuma definição de ficção aceita com universalidade. Também que "[...] the examination of fiction documents for information storage and retrieval needs to include as many examples of as many types of fiction as possible" (BEGHTOL, 1994, p.07).

Sendo os textos narrativos de ficção, então, objetos tão complexos e completos em si, pode-se pressupor que a representação em unidades de informação, seja, de alguma forma, afetada. Nesse contexto, Moraes (2012) 
Mariana da Silva Caprioli, Larissa de Mello Lima, Daniel Martínez-Avila, João Batista Ernesto de Moraes

Foucault: poder, vigilância, disciplina e punição uma análise do conceito de Panóptico em obra narrativa de ficção

afirma que, de fato, a classificação e indexação de ficção não é um problema discutido apenas nas últimas décadas, e que, presumivelmente, tomando como base Eriksson (2005), o primeiro artigo sobre o assunto surgiu em 1898, quando Ernest Baker, importante bibliotecário britânico escreveu sobre Classificação de fiç̧ão no Library World, ocorrendo uma discussão sobre o mesmo problema no início do século XX, na American Library Association (ALA).

Tem-se, então, a intenção de observar como uma análise de uma obra de ficção pode oferecer um conhecimento mais aprofundado do mesmo, podendo ajudar no momento de representar e, posteriormente, recuperar em unidades de informação.

\section{VIGIAR E PUNIR DE FOUCAULT}

Foucault escreveu "Vigiar e Punir" originalmente em 1975, na qual examina o nascimento das construções modernas de crime e punição, tratando de um exame dos mecanismos teóricos e sociais que influenciaram as mudanças nos sistemas penais ocidentais. O livro é embasado em documentos históricos franceses, porém as questões são atuais, sendo relevantes e importantes para as sociedades. É composto de quatro partes sendo elas: Suplício, Punição, Disciplina e Prisão. E, dessa forma, se dedica à análise de vigilâncias e punições presentes em vários âmbitos estatais, como prisões, ou hospitais, por exemplo.

Esse artigo tem como interesse principal o poder, a disciplina e a forma de vigilância proposta por Foucault em seu livro, porém, passa-se pela explanação de suplícios, nas quais o autor demonstra que se trata de uma pena corporal dolorosa, um modo de punição amplamente utilizada até o século XVIII, sendo o castigo proporcionalmente aplicado quanto à gravidade dos delitos.

Contudo, como coloca o autor, começou a acontecer o desaparecimento dos suplícios, para serem substituídos por "punições menos diretamente físicas, uma certa discrição na arte de fazer sofrer, um arranjo de sofrimentos 
Mariana da Silva Caprioli, Larissa de Mello Lima, Daniel Martínez-Avila, João Batista Ernesto de Moraes

Foucault: poder, vigilância, disciplina e punição uma análise do conceito de Panóptico em obra narrativa de ficção

mais sutis, mais velados e despojados de ostentação(...)" (FOUCAULT, 1987, p. 12). E ainda

(...) um fato é certo: em algumas dezenas de anos, desapareceu o corpo supliciado, esquartejado, amputado, marcado simbolicamente no rosto ou no ombro, exposto vivo ou morto, dado como espetáculo. Desapareceu o corpo como alvo principal da repressão penal (FOUCAULT, 1987, p.12).

Dessa forma, a cultura de expor a punição dos criminosos estava se desfazendo no final do século XVIII e começo do XIX e tudo que implicasse na exposição era visto como negativo. Não se pensava mais em mostrar às pessoas que os criminosos sofriam as consequências necessárias, para assim servir de exemplo, passa-se então a escondê-los, sendo colocados em um sistema de privação e de coação, de obrigações e interdições (FOUCAULT, 1987). O castigo não é mais o ato de infligir dor ao culpado, "o castigo passou de uma arte das sensações insuportáveis a uma economia dos direitos suspensos" (FOUCAULT, 1987, p.15).

Para podermos prosseguir, é imprescindível entender o conceito de poder em Foucault. Para ele o poder está ligado a direito e verdade, em uma relação triangular, na qual o poder como direito se manifesta peças formas que a sociedade se coloca e se movimenta, "ou seja, se há o rei, há também os súditos, se há leis que operam, há também os que a determinam e os que devem obediência" (FERREIRINHA; RAITZ, 2010, p.370). Já o poder como verdade se institui pelos discursos que produz, sendo sua obrigação, pelos movimentos ocasionados pela própria organização que o acomete e, por vezes, sem devida consciência e reflexão, isto é

[...]somos forçados a produzir a verdade pelo poder que exige essa verdade e que necessita dela para funcionar, temos de dizer a verdade, somos coagidos, somos condenados a confessar a verdade ou encontrá-la (FOUCAULT, 1999¹, p. 29). 
Mariana da Silva Caprioli, Larissa de Mello Lima, Daniel Martínez-Avila, João Batista Ernesto de Moraes

Foucault: poder, vigilância, disciplina e punição uma análise do conceito de Panóptico em obra narrativa de ficção

O autor dizia que as relações de poder postas, seja por qualquer instituição, escola ou prisão, são marcadas pela disciplina. É pela disciplina que as relações de poder são mais facilmente observadas.

Nesse contexto, observa-se sua noção de disciplina, que diz que "métodos que permitem o controle minucioso das operações do corpo, que realizam a sujeição constante de suas forças e Ihes impõem uma relação de docilidade-utilidade" (FOUCAULT, 1987, p.164). Ou seja, a suspensão dos direitos, quando levados a cárcere, se trata de um tipo de disciplina. A disciplina não apenas do corpo, mas também da alma, uma vez que as punições não são mais físicas, mas de restrição, de encarceramento, de tratamento psicológico, de observação médica, etc. As disciplinas são, na verdade, insumos de uma necessidade de controle e poder sobre a população, e podem ser aplicadas em fábricas, prisões, instituições de ensino, por exemplo (GUANDALINI; TOMIZAWA, 2013). Podemos falar do poder disciplinar que tem a função de "adestrar" para retirar e se apropriar ainda mais do indivíduo.

\begin{abstract}
Adestra as multidões confusas, móveis, inúteis de corpos e forças para uma multiplicidade de elementos individuais pequenas células separadas, autonomias orgânicas, identidades e continuidades genéticas, segmentos combinatórios (FOUCAULT, 1987, p.195).
\end{abstract}

Foucault (1987) ainda acredita que o sucesso do poder disciplinar se deve ao uso de instrumentos simples que ele chama de "o olhar hierárquico, a sanção normalizadora e sua combinação num procedimento que the é específico, o exame" (FOUCAULT, 1987, p.195). O olhar hierárquico também é chamado de vigilância hierárquica.

A disciplina é exercida, pressupõe-se, por um dispositivo que obrigue, pelo jogo de olhar, "um aparelho onde as técnicas que permitem ver induzam a efeitos de poder, e onde, em troca, os meios de coerção tornem claramente visíveis aqueles sobre quem se aplicam" (FOUCAULT, 1987, p.196). A vigilância hierárquica é aquela que simplesmente possibilita ver, sendo um sistema organizado, automático e anônimo. É possível observar ainda que a 
Mariana da Silva Caprioli, Larissa de Mello Lima, Daniel Martínez-Avila, João Batista Ernesto de Moraes

Foucault: poder, vigilância, disciplina e punição uma análise do conceito de Panóptico em obra narrativa de ficção

vigilância hierárquica se faz necessária em fábricas, escolas, hospitais, no exército, entre outros (GUANDALINI; TOMIZAWA, 2013).

A sanção normalizadora é a que comina, ou sanciona, toda pena. Segundo Foucault (1987, p.202)

$\mathrm{Na}$ essência de todos os sistemas disciplinares, funciona um pequeno mecanismo penal. É beneficiado por uma espécie de privilégio de justiça, com suas leis próprias, seus delitos especificados, suas formas particulares de sanção, suas instâncias de julgamento.

Então, se sanciona até mesmo o mais leve dos desvios de comportamento, funcionando como repressora de uma micropenalidade do tempo, da atividade, da maneira de ser, dos discursos, do corpo, da sexualidade. Assim

Trata-se ao mesmo tempo de tornar penalizáveis as frações mais tênues da conduta, e de dar uma função punitiva aos elementos aparentemente indiferentes do aparelho disciplinar: levando ao extremo, que tudo possa servir para punir a mínima coisa; que cada indivíduo se encontre preso numa universalidade punível-punidora (FOUCAULT, 1987, p.203).

Já o exame é o que combina a vigilância hierárquica e a sanção normalizadora, se tratando de um controle normalizante, vigilância que permite qualificar, classificar e punir. Tem por característica a elaboração de uma espécie de registro escrito dos resultados dos outros dois elementos.

Estabelece sobre os indivíduos uma visibilidade através das quais são diferenciados e sancionados. É por isso que, em todos os dispositivos de disciplina, o exame é altamente ritualizado. Nele vêm-se reunir a cerimônia do poder e a forma da experiência, a demonstração da força e o estabelecimento da verdade (FOUCAULT, 1987, p.209).

Outro lado desse elemento é a objetificação do indivíduo, dos quais se sabe exatamente as aptidões, ou ainda, uma importante ferramenta de comparação entre os indivíduos, permitindo identificar os desvios entre eles e a sociedade.

Foucault (1987) coloca que o poder disciplinar se deve ao uso desses instrumentos simples, eles demonstram a possibilidade de influência direta no 
Mariana da Silva Caprioli, Larissa de Mello Lima, Daniel Martínez-Avila, João Batista Ernesto de Moraes

Foucault: poder, vigilância, disciplina e punição uma análise do conceito de Panóptico em obra narrativa de ficção

indivíduo sem a necessidade da utilização de força física, moldando e convertendo um potencial inimigo da sociedade à um indivíduo útil na qual está inserido, o que confirma discurso do final do século XIX (GUANDALINI; TOMIZAWA, 2013).

E assim, Foucault (1987) traz o Panóptico, um modelo desses instrumentos pelo qual se pode visualizar e controlar todos em uma única pessoa, a qual não se sabe, necessariamente, que está sendo controlada.

\section{O PANÓPTICO DE FOUCAULT BASEADO EM BENTHAM}

O conceito de Panóptico foi concebido por Jeremy Bentham por volta de1787, como um plano inicial para uma casa de inspeção penitenciária. Tratava- se de um edifício circular onde os prisioneiros ocupavam celas separadas entre si, celas essas que partem da circunferência em forma de raios até o centro. Os inspetores ocupam o centro da circunferência, podendo ser chamado, segundo o autor de "alojamento do inspetor". Sugere, ainda, que haja um espaço entre o alojamento e as celas, chamando de "área intermediária ou anular", que tenha a largura necessária e que vá do exterior ao interior do alojamento. Ainda, cada cela teria sua janela que dá para o exterior, sendo suficientemente larga para iluminar a cela e fornecer luz a parte do alojamento. A parte interior da cela é composta de grade de ferro, que não obstrui a visão e vigilância do inspetor.

Bentham explana amplamente sobre a arquitetura do edifício, apenas posteriormente se preocupando com sua aplicabilidade, e nesse contexto,

(...) ver-se-á que ele é aplicável, penso eu, sem exceção, a todos e quaisquer estabelecimentos, nos quais, num espaço não demasiadamente grande para que possa ser controlado ou dirigido a partir de edifícios, queira-se manter sob inspeção um certo número de pessoas. Não importa quão diferentes, ou até mesmo quão opostos, sejam os propósitos: seja o de punir o incorrigível, encerrar o insano, reformar o viciado, confinar o suspeito, empregar o desocupado, manter o desassistido, curar o doente, instruir os que estejam dispostos em qualquer ramo da indústria, ou treinar a raça em ascensão no caminho da educação, em uma palavra, seja ele aplicado aos propósitos das prisões perpétuas na câmara da morte, ou prisões de 
Mariana da Silva Caprioli, Larissa de Mello Lima, Daniel Martínez-Avila, João Batista Ernesto de Moraes

Foucault: poder, vigilância, disciplina e punição uma análise do conceito de Panóptico em obra narrativa de ficção

confinamento antes do julgamento, ou casas penitenciárias, ou casas de correção, ou casas de trabalho, ou manufaturas, ou hospícios, ou hospitais, ou escolas (BENTHAM et al., 2008, p.19-20)

Ou seja, esse conceito pode ser aplicado a qualquer instituição que queira controlar um certo número de pessoas. E é exatamente onde Foucault (1987) encontrou seu ponto de apoio para uma teoria baseada nesta.

Foucault traz o conceito de Panóptico em seu livro "Vigiar e Punir", no capítulo III da Terceira Parte, intitulado "O Panoptismo" e se trata da análise mais conhecida do projeto de Bentham sobre o Panóptico. Foi publicado originalmente em Francês em 1975, seguindo os mesmo modelos arquitetônicos de seu autor base, trocando o "alojamento dos inspetores" por uma torre central com um vigia, trazendo também que nas celas deve-se trancar um louco, um doente, um condenado, um operário ou ainda um escolar, que são observados, mas não se veem, nem veem a quem os observa. Assim

O dispositivo panóptico organiza unidades espaciais que permitem ver sem parar e reconhecer imediatamente. Em suma, o princípio da masmorra é invertido; ou antes, de suas três funções - trancar, privar de luz e esconder - só se conserva a primeira e suprimem-se as outras duas. A plena luz e o olhar de um vigia captam melhor que a sombra, que finalmente protegia. A visibilidade é uma armadilha (FOUCAULT, 1987, p.223).

Então se trata de um dispositivo de aprisionamento, onde os indivíduos estão para cumprir sua pena, como no modelo de penitenciária da figura 1 abaixo, para curar suas doenças mentais ou físicas, ou aprender. É um dispositivo com garantia de ordem, uma vez que não podem ver uns aos outros, sendo também uma garantia de poder dos que observam, garantindo uma multiplicidade enumerável e controlável, e uma garantia de solidão sequestrada e olhada, dos que são observados. Assim, para Foucault (1987, p.225) "O Panóptico é uma máquina de dissociar o par ver-ser visto: no anel 
Mariana da Silva Caprioli, Larissa de Mello Lima, Daniel Martínez-Avila, João Batista Ernesto de Moraes

Foucault: poder, vigilância, disciplina e punição uma análise do conceito de Panóptico em obra narrativa de ficção

periférico, se é totalmente visto, sem nunca ver; na torre central, vê-se tudo, sem nunca ser visto".

Figura 1 - Modelo penitenciário de Willey Reveley, 1791 baseado em Foucault.

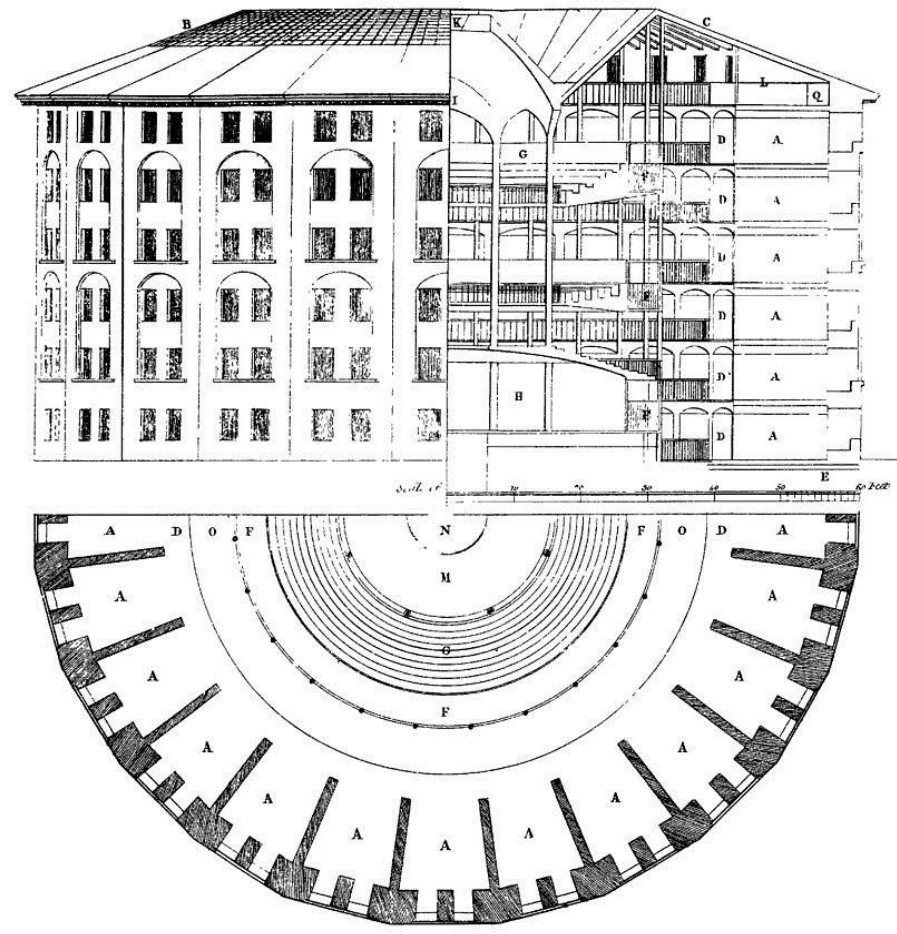

Fonte: Wikimedia Commons (2017) $)^{3}$

O Panóptico permite estabelecer diferenças:

nos doentes, observar os sintomas de cada um, sem que a proximidade dos leitos, a circulação dos miasmas, os efeitos do contágio misturem os quadros clínicos; nas crianças, anotar os desempenhos (sem que haja limitação ou cópia), perceber as aptidões, apreciar os caracteres, estabelecer classificações rigorosas e, em relação a uma evolução normal, distinguir o que é "preguiça e teimosia" do que é "imbecilidade incurável"; nos operários, anotar as aptidões de cada um, comparar o tempo que levam para fazer um serviço, e, se são pagos por dia, calcular seu salário em vista disso (FOUCAULT, 1987 p.226-227).

${ }^{3}$ Disponível em: https://commons.wikimedia.org/wiki/File:Panopticon.jpg?uselang=es 
Mariana da Silva Caprioli, Larissa de Mello Lima, Daniel Martínez-Avila, João Batista Ernesto de Moraes

Foucault: poder, vigilância, disciplina e punição uma análise do conceito de Panóptico em obra narrativa de ficção

Também pode ser pensado como máquina de fazer experiências com indivíduos, treinar ou retreiná-los, modificar seus comportamentos. Também testar diversas punições sobre os prisioneiros e procurar os mais eficazes.

E assim:

O Panóptico é um local privilegiado para tornar possível a experiência com homens, e para analisar com toda certeza as transformações que se pode obter neles. O Panóptico pode até constituir-se em aparelho de controle sobre seus próprios mecanismos. (...) O Panóptico funciona como uma espécie de laboratório de poder. Graças a seus mecanismos de observação, ganha em eficácia e em capacidade de penetração no comportamento dos homens; um aumento de saber vem se implantar em todas as frentes do poder, descobrindo objetos que devem ser conhecidos em todas as superfícies onde este se exerça (FOUCAULT, 1987, p.227228).

O efeito mais importante do Panóptico, segundo o autor, é induzir no detento um estado de consciente e permanente de visibilidade, se assegurando o funcionamento automático do poder. Também fazer com que a vigilância seja permanente em efeito, mesmo que descontínua em ações e, entre outros, que os detentos se encontrem presos numa situação de poder da qual são portadores (FOUCAULT, 1987).

Finalizando, para Foucault, o Panóptico deve ser compreendido como um modelo generalizável de funcionamento, definindo as relações de poder com a vida dos homens enquanto cotidiana. Observa que Bentham o apresenta como instituição particular, fechada em si mesma, mas não deve ser compreendido como edifício fantasioso. Deve ser visto como o diagrama de um mecanismo de poder levado a sua forma ideal que é, deve ser visto como uma figura de tecnologia política que se destaca de qualquer uso específico. Ponto em que se encaixa o próximo tópico do trabalho, sobre o livro Jogos Vorazes e seu conceito de Panem. 
Mariana da Silva Caprioli, Larissa de Mello Lima, Daniel Martínez-Avila, João Batista Ernesto de Moraes

Foucault: poder, vigilância, disciplina e punição uma análise do conceito de Panóptico em obra narrativa de ficção

\section{$5 \quad$ O LIVRO JOGOS VORAZES COM BASE NO PANÓPTICO}

O livro "Jogos Vorazes" foi escrito por Suzanne Collins, originalmente publicado em 2008, nos Estados Unidos sob o título de "The Hunger Games". No Brasil passou a ser publicado apenas em 2010, pela editora Rocco e se trata de uma trilogia de aventura e ação, construída em um cenário pósapocalíptico. É narrado em primeira pessoa, pela personagem principal Katniss Everdeen, uma garota de dezesseis anos que vive em um país incomum chamado Panem, o qual será tratado nesse artigo para a observação das aplicações do panóptico.

Panem é dominada por uma metrópole avançada em termos tecnológicos que se denomina "Capital", que organiza anualmente os chamados Jogos Vorazes para demonstrar seu poder sobre os cidadãos e trazer a lembrança constante da revolta ocorrida há décadas. A Capital é rodeada por doze distritos, mais pobres e menos desenvolvidos, definidos por uma sequência numérica de 1 a 12 . Anteriormente existia o décimo terceiro distrito, porém o mesmo foi destruído pela Capital por ter liderado uma rebelião e para evitar novas revoltas, os jogos foram criados.

Brevemente, para esses jogos são selecionados um garoto e uma garota de cada distrito, por meio de sorteio, durante o "Dia da Colheita", em uma transmissão ao vivo para a Capital. Esses selecionados devem ter entre doze e dezoito anos e são chamados de Tributos, sendo obrigatória sua participação. Os vinte e quatro escolhidos são enviados a uma arena controlada pela Capital, que a manipula com sua tecnologia avançada, e precisam lutar entre si até a morte, restando apenas um campeão ao final.

Panem é liderada por um presidente ditador, com ações tirânicas e é na Capital onde se suporta o domínio político e econômico do país. Impõe suas severas regras por meio de um exército de "Soldados da Paz" ou "Pacificadores" e, segundo algumas observações, se encontra a noroeste dos Estados Unidos, perto das Montanhas Rochosas, que atuam como uma barreira natural entre ela e os distritos, impedindo a entradas dos cidadãos e possibilitando ficar protegida. Ainda, existe o Edifício da Justiça, que representa um marco do poder sólido e presente da capital nos distritos. 
Mariana da Silva Caprioli, Larissa de Mello Lima, Daniel Martínez-Avila, João Batista Ernesto de Moraes

Foucault: poder, vigilância, disciplina e punição uma análise do conceito de Panóptico em obra narrativa de ficção

Os distritos são dispostos ao redor da Capital e são obrigados a enviar suprimentos para lá, sendo cada um responsável por um tipo. Existem muitas especulações de como essa disposição seria feita, uma vez que não há descrições no livro, e a seguir, na figura 2, existe um dos exemplos possíveis da disposição do país, estando a Capital no centro e os distritos a rodeando, bem como se imagina.

Figura 2 - Mapa de Panem.

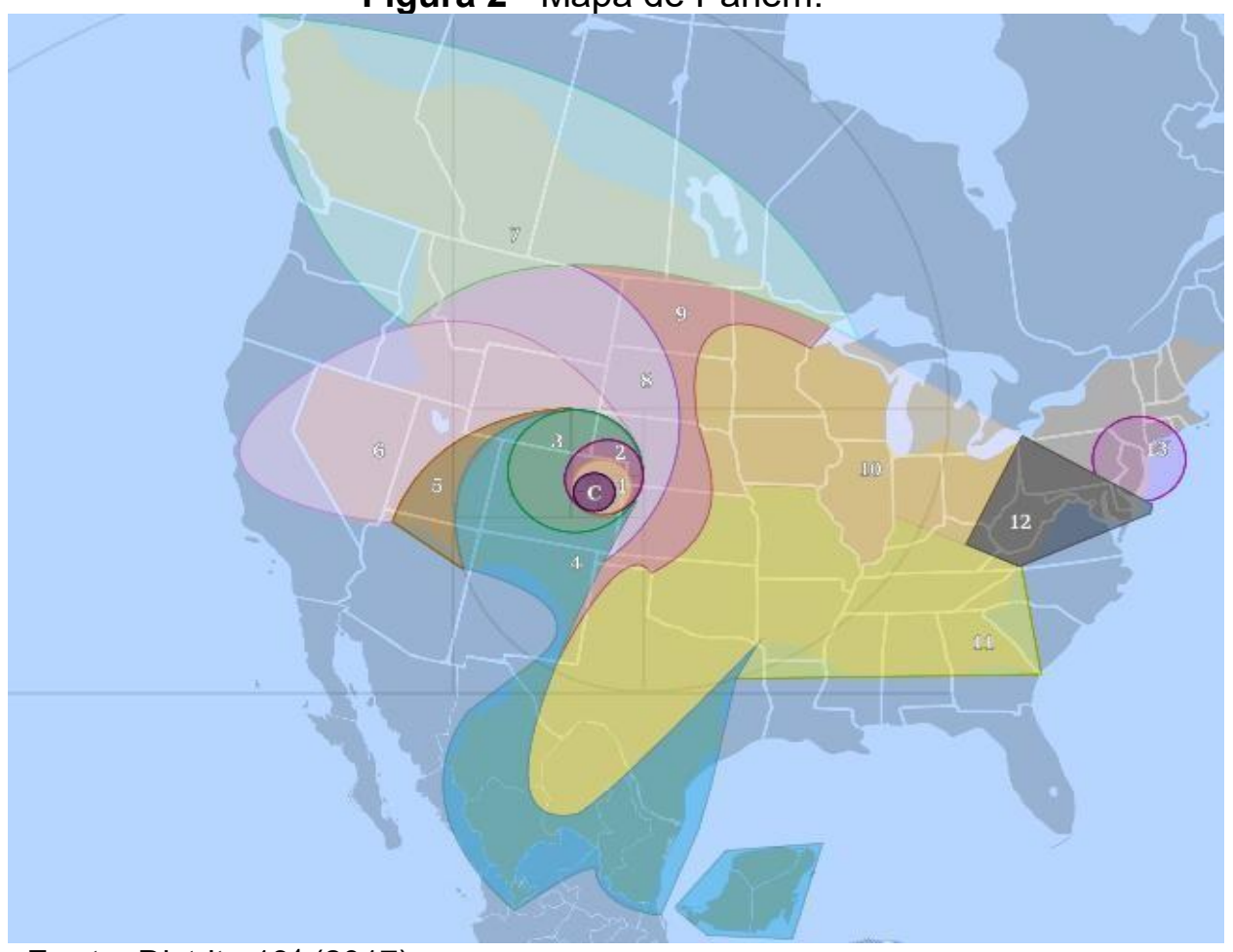

Fonte: Distrito $13^{4}(2017)$

Segundo a autora, a ideia do livro surgiu enquanto assistia TV e observou algumas cenas de um reality show e da Guerra no Iraque, percebendo que as duas coisas podiam estar interligadas de um modo inquietante. Afirmou que se baseou no mito grego de Teseu para as batalhas dos jogos, e ainda no fato de seu pai ter prestado serviço militar durante a Guerra do Vietnam e ter morrido em combate. O que leva ao próximo tópico, 
Mariana da Silva Caprioli, Larissa de Mello Lima, Daniel Martínez-Avila, João Batista Ernesto de Moraes

Foucault: poder, vigilância, disciplina e punição uma análise do conceito de Panóptico em obra narrativa de ficção

onde se discute como os conceitos de Foucault aparentam ser utilizados para descrever Panem e seus modelos de vigilância e punição.

\section{METODOLOGIA}

Este artigo trabalha com o segundo momento de Foucault e seu livro "Vigiar e Punir" (1987), explanando os conceitos de poder, disciplina, vigilância e punição, acarretando em um modelo de vigilância trabalhado pelo autor exemplificado na obra "Jogos Vorazes" de Suzanne Collins. A proposta aqui é uma análise de ambas as obras e um paralelo a fim de mostrar como os conceitos usados por Foucault são utilizados na narrativa de ficção de Collins.

Esse modelo de vigilância se traduz no Panóptico, e se interessa mostrar como foi concebido e como seria seu funcionamento, bem como, posteriormente, mostrar uma aplicação prática em um livro narrativo de ficção, para que a observação de que tal modelo pode ser eficiente.

\section{RESULTADOS E DISCUSSÃO}

O país descrito representa uma unidade de controle, imposição e punição perante os distritos, não existindo uma real preocupação com o bemestar físico e mental da população, apenas com o governo em si mesmo. Como visto, o Panóptico de Foucault se trata de um dispositivo de vigilância, onde, metaforicamente, pode-se imaginar a Panem dos livros.

Ela pode representar esse dispositivo por estabelecer a conduta que os distritos devem ter, contando com um edifício de comando e domínio, e mostrando que não existe lugar onde a Capital não estivesse vigiando.

A Capital controla seus cidadãos por meio dos jogos, o que mostra sua força e poder, mas também os controla em seus distritos, impedindo que haja contato entre eles e até mesmo com o centro de poder. A Capital é soberana e consegue observar a todos, sem ser observada, bem como propõe 0 Panóptico, sendo os distritos representam as celas que rodeiam a torre de observação com seu vigilante que tudo vê. 
Mariana da Silva Caprioli, Larissa de Mello Lima, Daniel Martínez-Avila, João Batista Ernesto de Moraes

Foucault: poder, vigilância, disciplina e punição uma análise do conceito de Panóptico em obra narrativa de ficção

Os jogos também podem ser observados como um exemplo de disciplina, onde os tributos são punidos abertamente, à vista de todos os cidadãos, como exemplo para que não haja mais revoltas e mostrando o poder de controle que a Capital tem.

Os procedimentos disciplinares reviram essa relação [de individualidade e o privilégio ligado a ela], abaixando o limite da individualidade descritível e fazem dessa descrição um meio de controle e um método de dominação. Não mais monumento para uma memória futura, mas documento para uma utilização eventual (FOUCAULT, 1987, p.215-216).

Os jogos são organizados uma vez ao ano, o único momento em que a Capital exerce seu poder diretamente aos distritos, e são organizados não para que sejam lembrados, mas sim para mostrar seu poder e que pode, e vai, voltar a acontecer. Segundo Foucault (1987, p.229) o Panóptico muitas vezes "é constituir um mecanismo de efeitos em cadeia", e o poder disciplinar é o centro da figura arquitetural do Panóptico, aqui exemplificado.

Nesse contexto, observa-se que a disciplina tem seu procedimento, em primeiro lugar, ligada à distribuição dos indivíduos em um espaço, sendo a técnica observada aqui a disciplina de cerca, que se trata da

(...) especificação de um local heterogêneo a todos os outros e fechado em si mesmo. Local protegido da monotonia disciplinar. Houve o grande "encarceramento" dos vagabundos e dos miseráveis; houve outros mais discretos, mas insidiosos e eficientes (FOUCAULT, 1987, p.168).

Ou seja, nos jogos os indivíduos são encarcerados ou cercados, em arenas montadas para que se ataquem até a morte, demonstrando o poder da Capital e a "domesticação" de seu povo.

Da mesma forma que esse tipo de encarceramento se torna um castigo ou punição disciplinar, que tem a função de reduzir os desvios, tem caráter essencialmente corretivo.

Como citado anteriormente, a punição disciplinar é tem poder de semelhança quanto a sua obrigação. Assim, castigar é disciplinar, e a disciplina, para Foucault (1987) precisa atender a certas exigências do momento histórico em que se encontra, que se trata da construção de uma 
Mariana da Silva Caprioli, Larissa de Mello Lima, Daniel Martínez-Avila, João Batista Ernesto de Moraes

Foucault: poder, vigilância, disciplina e punição uma análise do conceito de Panóptico em obra narrativa de ficção

máquina, em que seu efeito é levado ao máximo pela combinação articulada das peças elementares que a compõem. Ou seja, "A disciplina não é mais simplesmente uma arte de repartir os corpos, de extrair e acumular o tempo deles, mas de compor forças para obter um aparelho eficiente" (FOUCAULT, 1987, p.189). Esse aparelho eficiente vem a se consolidar no conceito do Panóptico.

Um dos lados do Panóptico pode ser que permite esclarecer as diferenças dos que estão nessa máquina, tomando como exemplo os distritos que rodeiam Panem, sendo cada um responsável por produzir um tipo de matéria prima, em que a Capital se interessa para seu sustento. Mas por outro lado, como vem sido explanado, o Panóptico pode ser usado como uma máquina de fazer experiências, modificar comportamento, treinar ou retreinar os indivíduos, entre outras coisas.

Com tais esclarecimentos, é possível observar na obra o perfeito encaixe no contexto em que a Capital se insere, com a intenção de corrigir a conduta de seus cidadãos, os tornando disciplinados da maneira que convinha aos donos do poder. O Panóptico pode ser observado como uma base teórica para a construção da obra, em que a disciplina e o poder são armas invisíveis e totalmente eficazes em seu tipo de governo. A Capital tudo observa e controla seus cidadãos, os disciplinando por meio dos jogos e também, com isso, mostrando seu poder eficaz.

O esquema panóptico é um intensificador para qualquer aparelho de poder: assegura sua economia (em material, em pessoal, em tempo); assegura sua eficácia por seu caráter preventivo, seu funcionamento contínuo e seus mecanismos automáticos. É uma maneira de obter poder (...). (FOUCAULT,1987, p.229).

O dispositivo não se trata apenas de um local de troca entre um mecanismo de poder e uma função, trata-se também de uma maneira de fazer funcionar as relações de poder numa função, e uma função por essas relações de poder (FOUCAULT, 1987).

Então, no livro se mostra um exemplo metafórico do Panóptico na forma de condução de uma sociedade soberana e punitiva, onde a disciplina, o poder 
Mariana da Silva Caprioli, Larissa de Mello Lima, Daniel Martínez-Avila, João Batista Ernesto de Moraes

Foucault: poder, vigilância, disciplina e punição uma análise do conceito de Panóptico em obra narrativa de ficção

e vigilância se mostram eficazes em manter uma sociedade "encarcerada", embora não seja um exemplo arquitetural do modelo, uma vez que não existe de forma clara a torre central com as celas circulares ao redor, apenas uma ideia do que possa ser.

\section{CONCLUSÃO}

Dessa forma, esse artigo demonstra que os conceitos do autor Foucault, como proposto inicialmente, ligados ao Panóptico e as forças de poder, vigilância e disciplina que o regem estão presentes no livro "Jogos Vorazes".

Ao tratar do Panóptico na visão do autor, explicitado no livro "Vigiar e Punir" foi possível observar como as forças de vigilância, poder e disciplina podem estar presentes em outros alguns modelos de sociedade, mesmo que fictícia, e não apenas em prisões, escolas ou hospitais.

Ainda, a análise do livro foi importante para ter um contato inicial com obras narrativas de ficção. Foi possível observar que um entendimento, ainda que superficial, da obra, pode vir a colaborar para uma melhor representação da mesma, pois a representação de obras narrativas de ficção em unidades de informação pode ser um tanto precária, embora venham sido mais estudadas ultimamente, pode haver uma série de desvios conceituais no momento de ser realizado o processo de recuperação temática da informação dessas obras.

É possível afirmar que este estudo buscou expor as forças de disciplina, poder e vigilância que regem o panóptico, estas são concomitantes tanto na obra de Foucault quanto na obra de fiç̧ão de Suzanne Collins, sendo assim percebe-se que os discursos do texto narrativo de ficção possuem paralelo direto com o discurso científico da obra de Michel Foucault.

Ainda é possível afirmar que a representação de obras narrativas de ficção é algo que possui importância, e esse ensaio pode possibilitar um contato primário com o que pode vir a ser tratado.

Com tal explanação, pode-se observar análise da sociedade do livro "Jogos Vorazes" que a mesma foi baseada no modelo do Panóptico e que os conceitos são aplicados, mesmo que não tenha ficado claro por parte da autora 
Mariana da Silva Caprioli, Larissa de Mello Lima, Daniel Martínez-Avila, João Batista Ernesto de Moraes

Foucault: poder, vigilância, disciplina e punição uma análise do conceito de Panóptico em obra narrativa de ficção

da obra que foram tomados como base. Ou seja, através da análise se observa que Panem, o país tratado no livro, pode ter sido inspirado no modelo do Panóptico e em seus preceitos, uma vez que há a constante vigilância de seus cidadãos, com um poder central que não pode ser facilmente alcançado e visto, com demonstrações claras de poder por meio da realização dos jogos anuais, bem como a validação do poder disciplinar, que se materializa também por meio dos jogos.

\section{REFERÊNCIAS}

A CAPITAL. In: Jogos Vorazes Wikia. Estados Unidos: Wikia Inc., 2016. Disponível em: <http://jogosvorazes.wikia.com/wiki/A Capital>. Acesso em: 06 jul. 2016.

BEGHTOL, C. The classification of fiction: the development of a system based on theoretical principles. Metuhen, NJ: Scarecrow Press, 1994.

BENTHAM, J. et al. O Panóptico. Belo Horizonte: Autêntica Editora, 2008.

CASTAÑON MORENO, B. Análisis temático documental. Investigación bibliotecológica, México, D.F., v. 6, n. 12, p. 4-10, Jan./Jun. 1992.

BRASCHER, M.; CAFÉ, L. Organização da Informação ou Organização do Conhecimento? In: ENCONTRO NACIONAL DE PESQUISA EM CIÊNCIA DA INFORMAÇÃO - ENANCIB, 9., 2008, São Paulo. Anais... São Paulo: USP, 2008. P. 1-14. Disponivel em: http://skat.ihmc.us/rid=1KR7TM7S9-S3HDKP5STP/BRASCHERCAF\%C3\%89 Acesso em: 09 fev. 2017>.

COLLINS, S. Jogos Vorazes. $1^{\text {a }}$ ed. São Paulo: Rocco, 2010.

ERIKSSON, R. The classification and indexing of imaginative literature. 16th ASIS\&T SIG/CR Classification Research Workshop, Charlotte: NC, October 29, 2005.

UM ESTUDO SOBRE O MAPA DE PANEM. In: Distrito 13, Brasil, 2011. Disponível em <http://www.distrito13.com.br/conteudo/info/mapa-de-panem/>. Acesso em: 08 jul. 2016. 
Mariana da Silva Caprioli, Larissa de Mello Lima, Daniel Martínez-Avila, João Batista Ernesto de Moraes

Foucault: poder, vigilância, disciplina e punição uma análise do conceito de Panóptico em obra narrativa de ficção

FERREIRA, T. F. Ensaio sobre a Sociedade em Jogos Vorazes. In: Tribo do Livro. Por um mundo de leitores. Brasil: Lomadee, 2012. Disponível em: $<$ http://www.tribodolivro.com/2012/05/ensaio-sobre-sociedade-em-jogosvorazes.html>. Acesso em: 08 jul. 2016.

FERREIRINHA, I. M. N.; RAITZ, T. R. As relações de poder em Michel Foucault: reflexões teóricas. Revista de Administração Pública. Rio de Janeiro, v.44, n.2, p.367-83, mar./abr., 2010. Disponível em:

<.http://www.scielo.br/pdf/rap/v44n2/08.pdf>. Acesso dia 06 jul.2016.

FOUCAULT. M. (1966). As palavras e as coisas. Trad. bras. Salma Tannus Muchail. 8ª Ed. São Paulo: Martins Fontes, 2000.

FOUCAULT, M. (1969). A Arqueologia do Saber. Trad. bras. Luis Felipe Baeta Neves. Rio de Janeiro: Forense Universitária, 1986.

FOUCAULT, M. (1971). A ordem do discurso. Trad. bras. de Laura Fraga Sampaio. São Paulo: Loyola, 1996.

FOUCAULT, M. (1975). Vigiar e Punir. História da Violência nas Prisões. Trad. bras. Raquel Ramalhete. 18ª . Ed. Petrópolis: Vozes, 1987.

FOUCAULT, M. (1976). História da Sexualidade 1. A vontade de Saber. Trad. bras. M. Thereza Albuquerque e J. A. Guilbon Albuquerque. 13a . Ed. Rio de Janeiro: Edições Graal, 1988.

FOUCAULT, M. (1983). Estruturalismo e pós-estruturalismo. In: Telos, vol. XVI, p. 195-2 11. Trad. bras. In: Motta, M.B. (Org). Michel Foucault. Arqueologia das Ciências e História dos Sistemasde Pensamento. (Col. Ditos \& Escritos II). Rio de Janeiro: Forense Universitária, 2000, p. 307-334.

FOUCAULT, M. (1984a) História da Sexualidade 2. O uso dos prazeres. Trad. bras. M. Thereza Albuquerque e J. A. Guilhon Albuquerque. Ed. Rio de Janeiro: Edições Graal, 2001.

FOUCAULT. M. (1984b). História da Sexualidade 3. O cuidado de si. Trad. Bras. M. Thereza Albuquerque e J. A. Guilhon Albuquerque. $7^{a}$. Ed. Rio de Janeiro: Edições Graal, 2002.

FOUCAULT, M. Em defesa da sociedade: curso no College de France (19751976). São Paulo: Martins Fontes, 1999.

FOUCAULT, M. The History of sexuality. London: Allen Lane, 1979. 
Mariana da Silva Caprioli, Larissa de Mello Lima, Daniel Martínez-Avila, João Batista Ernesto de Moraes

Foucault: poder, vigilância, disciplina e punição uma análise do conceito de Panóptico em obra narrativa de ficção

GARCIA-MARCO, F. J. et al. Knowledge organization on fiction and narrative documents: a challenge in the age of multimedia revolutions. In: GNOLLI, C.; MAZZOCCHI, F. (Org.). Paradigms and conceptual systems in knowledge organization. Würzburg: Ergon, p. 262-268, 2010.

GUNDALINI, B.; TOMIZAWA, G. Mecanismo Disciplinar de Foucault e o Panóptico de Bentham na Era da Informação. ANIMA: Revista Eletrônica do Curso de Direito das Faculdades OPET. Curitiba PR - Brasil. Ano 4, n. 9, jan/jun 2013. Disponível em: < http://anima-opet.com.br/pdf/anima9/anima9-2O-MECANISMO-DISCIPLINAR-DE-FOUCAULT-E-O-PANOPTICO-DEBENTHAM-NA-ERA-DA-INFORMACAO-Bruno-Guandalini-e-GuilhermeTomizawa.pdf>. Acesso em: 05 jul. 2016.

GREGOLIN, M. R. Foucault e Pêcheux na análise do discurso: diálogos \& Duelos. São Carlos: Editora Claraluz, 2006.

THE HUNGER GAMES. In: WIKIPÉDIA, a enciclopédia livre. Flórida: Wikimedia Foundation, 2016. Disponível em: $<$ https://pt.wikipedia.org/w/index.php?title=The Hunger Games\&oldid=461303 20>. Acesso em: 08 jul. 2016.

LECKIE, G J.; BUSCHMAN, J. E. Introduction: The Necessity for Theoretically Informed Critique in Library and Information Science (LIS). In: Leckie, G. J.; Given. L. M.; Buschman, J. E. Critical theory for library and information science: exploring the social from across the disciplines. Santa Barbara: Libraries Unlimited, p. xii-xxii, 2010. Disponível em: $<$ https://scholar.google.com/citations? user=c wg0C8AAAAJ\&hl=en $>$. Acesso em: 15 jul. 2016.

MAINGUENEAU, D. Nouvel les tendencies en analyse du discours. Paris: Hachette, 1987.

MORAES, J. B. E. A questão do aboutness no texto narrativo de ficção: perspectivas metodológicas para a Ciência da Informação. 93 f. Tese (Livredocência em Linguística e Documentação) - Departamento de Ciência da Informação da Faculdade de Filosofia e Ciências - Unesp, Marília, 2011.

MORAES, J. B. E. Aboutness in Fiction: Methodological Perspectives for Knowledge Organization. In: INTERNATIONAL ISKO CONFERENCE (INDIA CHAPTER): CATEGORIES, RELATIONS AND CONTEXT IN KNOWLENDGE ORGANIZATION, 12., 2012, Índia (Mysore). Conferência. Índia, 2012. p. 01 10. 
Mariana da Silva Caprioli, Larissa de Mello Lima, Daniel Martínez-Avila, João Batista Ernesto de Moraes

Foucault: poder, vigilância, disciplina e punição uma análise do conceito de Panóptico em obra narrativa de ficção

NOVELLINO, M. S. F. Instrumentos e metodologias de Representação da Informação. Inf. Inf., Londrina, v. 1, n. 2, p.37-45, jun./dez. 1996. Disponível em: <http://www.uel.br/revistas/uel/index.php/informacao/article/view/1603>. Acesso em: 10 jan. 2017.

PANÓPTICO. In: WIKIPÉDIA, a enciclopédia livre. Flórida: Wikimedia Foundation, 2015. Disponível em:

$<$ https://pt.wikipedia.org/w/index.php?title=Pan\%C3\%B3ptico\&oldid=43287911. Acesso em: 08 jul. 2016.

PINHO, F. A.; NASCIMENTO, B. L. C. do; MELO, W. L. As dimensões ôntica, epistêmia e documental na representação da informação e do conhecimento. ACB: Biblioteconomia em Santa Catarina, Florianópolis, v. 20, n. 1, p.112123, jan./abr. 2015. Disponível em: <https://revista.acbsc.org.br/racb/article/view/995/pdf 114>. Acesso em: 15 jan. 2017.

RAFFERTY, $P$. The representation of knowledge in library classification schemes. Knowledge Oganization. Wuzburg, v. 28, n. 4, p. 180-191, 2001.

RAJCHMAN, J. (1989). Foucault: a ética e a obra. In: Rencontre Internationale Michel Foucault Filosophe. Paris: Seuil. Trad. Bra. Wanderson Flor do Nascimento, 1989.

SABBAG, D. M. A. Análise documental em textos narrativos de ficção: subsídios para o processo de análise. 160 f. Tese (Doutorado em Ciência da Informação/ Informação, tecnologia e conhecimento) - Faculdade de Filosofia e Ciências, Universidade Estadual Paulista, Marília, 2013. Disponível em: $<$ http://www.marilia.unesp.br/Home/PosGraduacao/Cienciadalnformacao/Disser tacoes/SABBAG Deise Maria Antonio.pdf>. Acesso em: 05 set. 2015.

\title{
Title
}

Foucault: power, surveillance, discipline and punishment an analysis of the concept of panoptic in narrative fiction work

\begin{abstract}
Introduction: Narrative fiction, such as Suzanne Collins' "Hunger Games", can be about concepts and topics that could be useful in the academic study of surveillance, punishment, discipline, and power. Objective: We aim to draw a parallel between Jeremy Bentham's concept of Panopticon (developed by Foucault in "Discipline and Punish") and the book "Hunger Games." We work with the hypothesis that Panem, the country described in the book is inspired by Panoptism, or the Panopticon device. Methodology: This is a review article that, in a first moment, provides a description of how Foucault used the concept of Panopticon in "Discipline and Punish", and in a second moment explores the concept of Panopticon in relation to the book "Hunger
\end{abstract}


Mariana da Silva Caprioli, Larissa de Mello Lima, Daniel Martínez-Avila, João Batista Ernesto de Moraes

Foucault: poder, vigilância, disciplina e punição uma análise do conceito de Panóptico em obra narrativa de ficção

Games" to corroborate our hypothesis. Results: We perceive that the forces of surveillance, power and discipline that govern the Panopticon are present in both Foucault's work and Suzanne Collins's work, showing that this fictional discourse presents common elements with Michel Foucault's work. Conclusion: As the works of fiction can present elements that are common to non-fiction works. The representation of narrative works of fiction is something that has potential importance for the study of certain concepts in the academia. This aspect needs to be considered and explored in relation to the description of fiction.

Keywords: Scientific Discourse; Literary Discourse; "Surveiller et Punir"; "Hunger Games"; Thematic representation of the document.

\title{
Titulo
}

Foucault: poder, vigilancia, disciplina y punición una análisis del concepto de panóptico en obra narrativa de ficción

\begin{abstract}
Resumen
Introducción: Textos narrativos de ficción, como por ejemplo el libro "Juegos Voraces" de Suzanne Collins, pueden tratar conceptos y temar que pueden ser de utilidad en el estudio científico de la vigilancia, el castigo, la disciplina y el poder. Objetivo: Realizar un paralelo entre el concepto de Panóptico concebido por Jeremy Bentham, y trabajado por Foucault en su obra "Vigilar y castigar", con el libro "Juegos voraces", partiendo de la hipótesis de que Panem, el país tratado en la historia del libro Collins, está inspirado en el Panoptismo y el dispositivo de Panóptico. Metodología: Se trata de un artículo de revisión que busca en un primer momento reflexionar sobre la forma en que Foucault utilizó el concepto de Panóptico en "Vigilar y castigar", para en un segundo momento profundizar el concepto de Panóptico con relación a la obra de ficción "Juegos voraces" buscando elementos que corroboren la hipótesis del artículo. Resultados: Se muestra que las fuerzas de vigilancia, poder y disciplina que rigen el Panóptico son concomitantes en la obra de Foucault y en la obra de ficción de Suzanne Collins escrita en 2010, haciéndonos percibir que los discursos del texto narrativo de ficción tienen consonancia con el discurso científico de la obra de Michel Foucault. Conclusiones: Ya que las obras de ficción pueden presentar elementos comunes a los trabajos de no ficción. La representación de obras narrativas de ficción es algo que tiene potencial importancia en el estudio de conceptos en áreas académicas. Éste es aspecto que necesita ser considerado y estudiado en mayor profundidad con relación a la descripción de obras de ficción
\end{abstract}

Palabras clave: Discurso Científico; Discurso Literario; "Vigilar y castigar"; "Los Juegos del Hambre"; Representación temática del documento.

Recebido em: 26.06.2017

Aceito em: 04.12.2017 